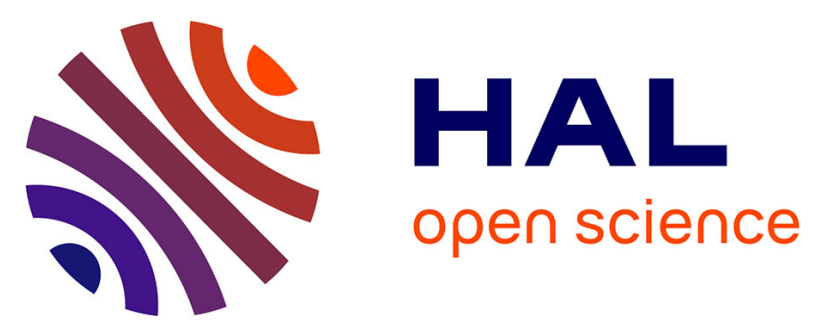

\title{
The phosphoinositide 3-kinase pathway and glycogen synthase kinase-3 positively regulate the activity of metal-responsive transcription factor-1 in response to zinc ions
}

Yannick Andéol, Jessica Bonneau, Laurence M. Gagné, Kévin Jacquet, Véronique Rivest, Marc-Étienne Huot, Carl Séguin

\section{To cite this version:}

Yannick Andéol, Jessica Bonneau, Laurence M. Gagné, Kévin Jacquet, Véronique Rivest, et al.. The phosphoinositide 3-kinase pathway and glycogen synthase kinase-3 positively regulate the activity of metal-responsive transcription factor-1 in response to zinc ions. Biochemistry and Cell Biology, 2018, 96 (6), pp.726-733. 10.1139/bcb-2018-0073 . hal-01980017

\section{HAL Id: hal-01980017 \\ https://hal.sorbonne-universite.fr/hal-01980017}

Submitted on 14 Jan 2019

HAL is a multi-disciplinary open access archive for the deposit and dissemination of scientific research documents, whether they are published or not. The documents may come from teaching and research institutions in France or abroad, or from public or private research centers.
L'archive ouverte pluridisciplinaire HAL, est destinée au dépôt et à la diffusion de documents scientifiques de niveau recherche, publiés ou non, émanant des établissements d'enseignement et de recherche français ou étrangers, des laboratoires publics ou privés. 


\title{
The phosphoinositide 3-kinase pathway and glycogen synthase kinase-3 positively regulate the activity of metal-responsive transcription factor- 1 in response to zinc ions
}

\author{
Yannick Andéol, Jessica Bonneau, Laurence M. Gagné, Kevin Jacquet, Véronique Rivest, \\ Marc-Étienne Huot, and Carl Séguin
}

\begin{abstract}
Metal-responsive transcription factor-1 (MTF-1) is a metal-regulatory transcription factor essential for induction of the genes encoding metallothioneins (MTs) in response to transition metal ions. Activation of MTF-1 is dependent on the interaction of zinc with the zinc fingers of the protein. In addition, phosphorylation is essential for MTF-1 transactivation. We previously showed that inhibition of phosphoinositide 3-kinase (PI3K) abrogated Mt expression and metal-induced MTF-1 activation in human hepatocellular carcinoma (HCC) HepG2 and mouse L cells, thus showing that the PI3K signaling pathway positively regulates MTF-1 activity and Mt gene expression. However, it has also been reported that inhibition of PI3K has no significant effects on Mt expression in immortalized epithelial cells and increases Mt expression in HCC cells. To further characterize the role of the PI3K pathway on the activity of MTF-1, transfection experiments were performed in HEK293 and HepG2 cells in presence of glycogen synthase kinase-3 (GSK-3), mTOR-C1, and mTOR-C2 inhibitors, as well as of siRNAs targeting Phosphatase and TENsin homolog (PTEN). We showed that inhibition of the mTOR-C2 complex inhibits the activity of MTF-1 in HepG2 and HEK293 cells, while inhibition of the mTOR-C1 complex or of PTEN stimulates MTF-1 activity in HEK293 cells. These results confirm that the PI3K pathway positively regulates MTF-1 activity. Finally, we showed that GSK-3 is required for MTF- 1 activation in response to zinc ions.
\end{abstract}

Key words: metal-responsive transcription factor-1 (MTF-1), glycogen synthase kinase-3 (GSK-3), phosphatase and TENsin homolog (PTEN), mTOR-C1, mTOR-C2.

Résumé : Le facteur de transcription MTF-1 (« Metal-responsive transcription factor-1 ») est essentiel à l'induction des gènes des métallothionéines (MT) en réponse aux ions de métaux de transition. L'activation de MTF-1 dépend de la liaison des ions de zinc avec les doigts de zinc de la protéine. En outre, la phosphorylation de MTF-1 est essentielle à son activation par les métaux. Nous avons précédemment montré que l'inhibition de la phosphoinositide 3-kinase (PI3K) inhibe l'expression des Mt et l'activation de MTF-1 en réponse aux métaux, dans des cellules d'hépatocarcinome humaines HepG2 et des cellules L de souris, démontrant ainsi que la voie de signalisation PI3K contrôle l'activité de MTF-1 et l'expression des Mt de façon positive. Cependant, il a aussi été rapporté que l'inhibition de PI3K n'a pas d'effets significatifs sur l'expression des Mt dans des cellules épithéliales immortalisées, et qu'elle stimule l'expression des Mt dans les cellules d'hépatocarcinome. Dans le but de réévaluer le rôle de la voie de signalisation PI3K sur l'activité de MTF-1, des expériences de transfection ont été réalisées dans des cellules HEK293 et HepG2, en présence d'inhibiteurs de la glycogène synthase kinase-3 (GSK-3) et des complexes mTOR-C1 et mTOR-C2, ainsi que d'ARN interférents dirigés contre la "Phosphatase and TENsin homolog (PTEN) ». Nous montrons que l'inhibition du complexe mTOR-C2 inhibe l'activation de MTF-1 dans des cellules HepG2 et HEK293, alors que l'inhibition du complexe mTOR-C1 ou de PTEN stimule l'activité de MTF-1 dans des cellules HEK293. Ces résultats confirment que la voie PI3K active MTF-1. Finalement, nous montrons que GSK-3 est requise pour l'activation de MTF-1 en réponse aux ions de zinc.

Mots-clés : MTF-1, glycogène synthase kinase-3 (GSK-3), « Phosphatase and TENsin homolog (PTEN) », mTOR-C1, mTOR-C2.

\section{Introduction}

Metal-responsive transcription factor-1 (MTF-1), a Zn-finger protein highly conserved in vertebrates from pufferfish to humans (Lichtlen and Schaffner 2001; Günther et al. 2012), was originally isolated as the transcription factor that controls metallothionein (Mt) gene expression in response to metal ions. MTs are small, cysteine-rich, metal binding multifunctional stress proteins pres- ent in various tissues and cell types from yeast to humans (Coyle et al. 2002; Babula et al. 2012). MTs play important roles in zinc and copper homeostasis, detoxification of toxic metals, and radical scavenging. MTs have also been associated with multi-drug resistance (Okazaki et al. 1998) and protection against cisplatin renal toxicity (Satoh et al. 1997). Metal activation of Mt gene transcription depends on the presence of regulatory DNA sequences termed metal

Y. Andéol. Équipe Enzymologie de l’ARN, ER6, 9 quai St Bernard, Faculté des Sciences et Technologies, Sorbonne-Université, 75252 Paris, Cedex 05, France.

J. Bonneau, ${ }^{*}$ L. M. Gagné,* K. Jacquet,* V. Rivest, M.-É. Huot, and C. Séguin. Département de biologie moléculaire, de biochimie médicale et de pathologie, Faculté de médecine, Université Laval and Centre de recherche du CHU de Québec, Axe Oncologie, Hôtel Dieu de Québec, 9 rue McMahon, Québec, QC G1R 3S3, Canada.

Corresponding author: Carl Séguin (email: Carl.Seguin@fmed.ulaval.ca).

*These three authors made equal contributions to the study. 
regulatory elements (MREs), and involves the transcription factor MTF-1 interacting with the MREs in a zinc-dependent manner (Günther et al. 2012; Grzywacz et al. 2015).

MTF-1 is essential for basal and metal-induced Mt transcription. Notably, the $M t f-1$ gene is essential, as $M t f-1$ knock-out (KO) mice die in utero due to liver degeneration and oedema (Günes et al. 1998). MTF-1 regulates the expression of several genes, including those encoding placenta growth factor (Green et al. 2001), several zinc transporters (Zhao et al. 2014), the human prion protein (Bellingham et al. 2009), and mir132 miRNA (Lee et al. 2007). Knocking-down MTF-1 with siRNAs changes the transcriptional response to zinc for over 1000 genes (Hogstrand et al. 2008). Furthermore, MTF-1 increases lifespan (Bahadorani et al. 2010), activates expression of $\beta$-synuclein, a protein relevant to neurodegeneration (McHugh et al. 2011), and has been associated with epileptogenesis (van Loo et al. 2015), osteoarthritis (Kim et al. 2014), and increased susceptibility to thrombosis and coronary heart disease (Ding et al. 2010). In addition, the results from numerous studies support an important role of MTF-1 in tumour initiation and progression to malignant growth. Notably, using xenograft implantation of wild type or MTF-1-KO simian virus 40 large $\mathrm{T}$ antigen immortalized, and Harvey-ras-transformed mouse embryonic fibroblasts, it has been shown that the loss of MTF-1 suppresses tumour growth (Haroon et al. 2004). MTF-1 protein levels are elevated in diverse human tumour types, including breast, lung, cervical, and kidney carcinomas (Shi et al. 2010). Taken together, these observations suggest that MTF-1 plays a general role in the cellular stress response and support the concept that MTF-1 is an important multi-stress sensor.

MTF-1 is a cytoplasmic zinc sensor, characterized by increased DNA-binding activity upon zinc treatment (Heuchel et al. 1994; Giedroc et al. 2001; Laity and Andrews 2007). Activation of MTF-1 is dependent on the interaction of zinc with the zinc fingers of the protein (Bittel et al. 2000). While direct and reversible activation of MRE-binding affinity of MTF-1 by zinc is necessary for activation of $M t$ gene expression, it is not sufficient for zinc induction of gene expression in vivo (Smirnova et al. 2000). In addition, phosphorylation is essential for MTF-1 transactivation in response to zinc and cadmium ions, and is controlled by a complex kinase signal transduction pathway that includes protein kinase C (PKC), phosphoinositide 3-kinase (PI3K), c-Jun N-terminal kinase, casein kinase-2 (CK2), Phosphatase and TENsin homolog (PTEN), protein phosphatase 2A (PP2A), and a protein tyrosine kinase (LaRochelle et al. 2001; Saydam et al. 2002; Lin et al. 2012; Chen et al. 2014).

We previously showed that inhibition of PI3K with wortmannin and LY294002 completely abrogated metal induction of Mt mRNA in L cells, as assayed by Northern analysis (LaRochelle et al. 2001). In addition, we showed that LY294002 diminished metal-induced expression of an MTF-1-specific luciferase (LUC) reporter plasmid (MRE-LUC) by $60 \%-70 \%$, as assayed by transfection experiments in HepG2 cells. Taken together, these results show that the PI3K signaling pathway positively regulates MTF-1 activity and Mt gene expression. However, Datta et al. (2007) showed that inhibition of PI3K has no significant effects on either basal or zinc-induced Mt2A and Mt1 expression in immortalized human-liver-derived THLE-2 epithelial cells, as assayed by reverse-transcription PCR, although it increased basal and zinc-induced expression of Mt1 and Mt2A gene expression in human hepatocellular carcinoma (HCC) Hep3B and HepG2 cells, as assayed by reverse-transcription PCR and by transient transfections. According to the interpretation of Datta et al. (2007), Mt gene expression is downregulated in HCC because the PI3K pathway is activated in these cancer cells, thus inactivating glycogen synthase kinase-3 (GSK-3), a downstream effector of PI3K. GSK-3 phosphorylates and activates CCAAT/enhancer binding protein $\alpha(\mathrm{C} / \mathrm{EBP} \alpha)$, which then could interact with MTF-1 and together induce Mt gene expression. Thus, PI3K would negatively regulate $M t$ activation by inactivating GSK-3. Given that the effect of the PI3K pathway on the activity of
MTF-1 and Mt gene expression remains controversial, we further analyzed the role of this pathway on the activation of MTF-1 in response to zinc ions.

Upon activation by a receptor tyrosine kinase or RAS, PI3K produces $\operatorname{PI}(3,4,5) \mathrm{P}_{3}$, which serves as a docking site for two serine/ threonine kinases [protein kinase B/Akt (Akt) and phosphoinositidedependent kinase-1 (PDK1)] and brings them into proximity at the plasma membrane (Dibble and Cantley 2015). Akt is then phosphorylated and activated by PDK1 and by the mechanistic target of the rapamycin (mTOR) complex 2 (mTOR-C2). Once activated, Akt phosphorylates various target proteins at the plasma membrane, the cytosol, and the nucleus (Manning and Toker 2017). A central target of Akt is mTOR in complex 1 (mTOR-C1), which stimulates cell growth, both by promoting ribosome production and protein synthesis and by inhibiting protein degradation (Laplante and Sabatini 2012). Akt activates mTOR-C1 indirectly by phosphorylating and thereby inhibiting tuberous sclerosis complex 2 (TSC2), a negative regulator of mTOR-C1. Another important target phosphorylated and inhibited by activated Akt is GSK-3, active in several central intracellular signaling responses, including cellular proliferation, migration, glucose regulation, and apoptosis (Hermida et al. 2017). Finally, PTEN can dephosphorylate $\mathrm{PI}(3,4,5) \mathrm{P}_{3}$, and is involved in the downregulation of the pathway (summarized in Fig. 5).

Because the PI3K inhibitor LY294002 used in the previous studies affects other kinases such as GSK-3 and CK2 (Gharbi et al. 2007), in this study, we used rapamycin, a mTOR-C1 specific inhibitor (Brown et al. 1994; Gulhati et al. 2009), and Torin 1, which inhibits both mTOR-C1 and mTOR-C2 (Hoang et al. 2010; Janes et al. 2010). We also used specific short interfering RNAs (siRNAs) to inhibit PTEN. We confirmed that the PI3K pathway positively regulates the activity of MTF-1. In addition, we showed that GSK-3 is required for MTF-1 activation in response to zinc ions.

\section{Materials and methods}

\section{Reagents and plasmid constructs}

The protein kinase inhibitors Torin 1, rapamycin, LY2090314, and CHIR99021 were purchased from Selleckchem (Houston, Texas, USA), whereas PTEN (sc-29459) and negative control (sc37007) siRNAs were from Santa Cruz Biotechnology, Inc. (Dallas, Tex.). All other chemicals were purchased from Sigma-Aldrich (Oakville, Ontario, Canada). The LUC reporter plasmid MT1-LUC contains $1843 \mathrm{bp}$ of the $5^{\prime}$ flanking region and $68 \mathrm{bp}$ of the $5^{\prime}$ untranslated region from the mouse Mt1 gene (Faraonio et al. 2000). Similarly, the plasmid MT2A-LUC contains a human Mt2A gene DNA fragment (positions -780 to +65 ) cloned into pGL2 basic (Promega, Madison, Wisconsin, USA) (Dubé et al. 2011). To construct plasmid (MREd) ${ }_{6}$-LUC, a synthetic DNA fragment containing 6 mouse Mt1 MREd elements (Labbé et al. 1991) (5 elements in direct tandem orientation and the 6th in the opposite orientation) was cloned in front of a minimal mouse Mt1 promoter DNA fragment (positions -35 to -68 ) into the LUC reporter plasmid pGL2Basic (Promega, Madison, Wis.). TOP-Flash and FOP-Flash plasmids were purchased from Upstate (Temecula, California, USA).

\section{Cell culture, transfection, and immunoblotting}

Human HEK293 cells (at passage 3) were obtained from M. Caruso (Centre de Recherche du CHU de Québec), and human HepG2 cells (at passage 109) were from A. Anderson (Centre de Recherche du CHU de Québec). Cells were grown in Dulbecco's modified Eagle's medium (DMEM) supplemented with 10\% fetal bovine serum (FBS), and each culture was never used for more than for 8-10 passages. Where indicated, protein kinase inhibitors were added $30 \mathrm{~min}$ prior to the direct addition of metals and maintained during the remainder of the incubation period. Protein kinase inhibitors were dissolved in $\mathrm{Me}_{2} \mathrm{SO}$ as a $5 \mathrm{mmol} / \mathrm{L}$ stock solution and stored at $-80^{\circ} \mathrm{C}$. 
Fig. 1. Effect of Torin 1 on (MREd) 6 -LUC (MRE-LUC) (A), MT1-LUC (mMT1) (B), and MT2A-LUC (hMT2A) (C) expression. HEK293 (A) and HepG2 (B and C) cells transfected with the different reporter plasmids, as indicated, were serum-starved and pre-incubated for 30 min with the vehicle alone (0) or with 100 or $250 \mathrm{nmol} / \mathrm{L}$ of Torin 1 , as indicated below the graphs, and then treated or not with $100 \mu \mathrm{mol} / \mathrm{L} \mathrm{ZnCl} \mathrm{f}_{2}$ for $16 \mathrm{~h}$. Cell extracts were prepared, and measurement of LUC activity was performed with a dual LUC kit. Results are expressed as firefly LUC (fLUC) activity per microgram $(\mu \mathrm{g})$ of total protein, and as a percentage relative to that of the control induced by zinc, which is taken as $100 \%$. The data represent the mean \pm S.D. of 3 independent experiments performed in triplicate. Significant differences between the control and treated samples are based on the one-way ANOVA followed by a Bonferroni post-hoc test $\left({ }^{*}, p \leq 0.05 ;{ }^{* * *}, p<0.0001\right)$.

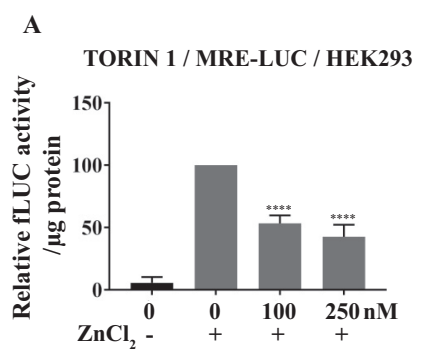

B TORIN 1 / mMT1 / HepG2

C

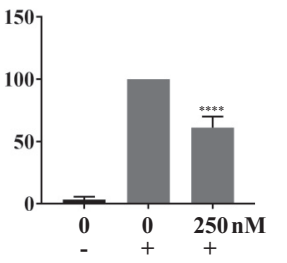

TORIN 1 / hMT2A / HepG2

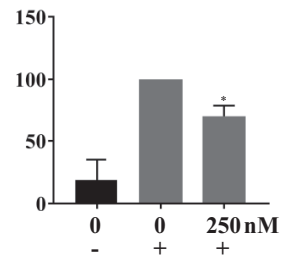

In the experiments with the protein kinase inhibitors, cells were transfected with the different plasmids using linear polyethylenimine (PEI; Polysciences, Warrington, Pennsylvania, USA) (Roy et al. 2010). Briefly, $2 \mu \mathrm{g}$ of PEI per microgram of DNA were mixed in $100 \mu \mathrm{L}$ of serum free DMEM for $5 \mathrm{~min}$. The mixture was then added to the cells containing $1 \mathrm{~mL}$ of DMEM with $10 \%$ FBS. Cells were seeded in 12 -well plates $\left(7 \times 10^{4}\right.$ cells/well) $24 \mathrm{~h}$ prior to transfection, then exposed to the DNA precipitate for $6 \mathrm{~h}$. Cells were then serum-starved ( $0.1 \% \mathrm{FBS})$, treated, or not, with inhibitors and $100 \mu \mathrm{mol} / \mathrm{L} \mathrm{ZnCl}_{2}$, and harvested $16 \mathrm{~h}$ later. Firefly LUC activity was determined with a Dual-LUC assay kit (Promega), according to the recommendations of the manufacturer, and normalized to total cellular protein contents. Protein concentrations were determined with the Bio-Rad Bradford Protein Assay (BioRad Laboratories, Mississauga, Ont.).

In the experiments with the PTEN siRNAs, cells were transfected with the reporter plasmid together with control or PTEN siRNAs $(0.125 \mu \mathrm{g} / \mu \mathrm{L})$ by the calcium phosphate method (Sambrook et al. 1989). Briefly, cells were seeded in 12 well plates $\left(7 \times 10^{4}\right.$ cells/well $)$ $24 \mathrm{~h}$ prior to transfection. Cells were transfected with $1 \mu \mathrm{g}$ of the reporter plasmid (MREd) ${ }_{6}$-LUC and different concentrations of control or PTEN siRNAs, as indicated in the figure legends, shocked for $1 \mathrm{~min}$ at $37{ }^{\circ} \mathrm{C}$ with $10 \%$ glycerol in HEPES-buffered saline and incubated for $24 \mathrm{~h}$ in growth medium. Cells were then serum-starved (0.1\% FBS), treated, or not, with $100 \mu \mathrm{mol} / \mathrm{L} \mathrm{ZnCl}_{2}$, and harvested after $16 \mathrm{~h}$. The plasmid pTK-rLUC (Promega) was used as an internal standard to monitor transfection efficiency. The total amount of DNA added to the cells was adjusted to $4 \mu \mathrm{g}$ per well with salmon sperm DNA. LUC activities were determined with a Dual-LUC assay kit (Promega) and expressed as a ratio of firefly LUC activity over Renilla LUC activity. The value presented for each transfected test plasmid corresponds to the mean of at least 3 separate transfections performed in triplicate. In each experiment, cells were examined under the microscope to make sure that their appearance and morphology were normal as compared to the control cells. Statistical significance was determined via one-way ANOVA followed by a Bonferroni post-hoc test using Prism 7 software (GraphPad) $\left(^{*}, p \leq 0.05\right.$; **, $p \leq 0.01$; ${ }^{* * *}, p \leq 0.001$; **** $p<0.0001$ ).

For immunoblotting experiments, cells were washed in phosphate-buffered saline (PBS) and recovered by scraping in Laemmli buffer [ 90 mmol/L Tris- $\mathrm{HCl}$ (pH 6.8), 15\% glycerol, $3 \%$ sodium dodecyl sulphate (SDS)]. Lysates were heated to $95^{\circ} \mathrm{C}$ for $8 \mathrm{~min}$ and clarified by centrifugation at $15000 \mathrm{~g}$ for $10 \mathrm{~min}$. Proteins were resolved on $10 \%$ SDS-polyacrylamide gels and transferred to an Immun-Blot PVDF membrane (Bio-Rad, Mississauga, Ont.). The membrane was blocked in 5\% non-fat milk in PBS-Tween 0,1\%, incubated with anti-S6 (54D2,

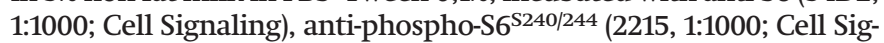
naling), anti-AKT (C67E7, 1:1000; Cell Signaling), anti-phosphoAKT $^{\text {S473 }}$ (9271, 1:1000; Cell Signaling), anti-phospho-AKT ${ }^{\text {T308 }}$ (C31E5E,
1:1000; Cell Signaling), anti-PTEN (D4.3, 1:1000; Cell Signaling), or anti-GAPDH (D16H11, 1:1000; Cell Signaling) antibodies, washed in PBS-Tween $0,1 \%$, and incubated with horseradish-peroxidaseconjugated anti-IgG secondary antibodies. Proteins were visualized using Western Lightning Plus (PerkinElmer, Massachusetts, USA). Protein loading was normalized using anti-GAPDH (D16H11, 1:1000; Cell Signaling).

\section{Results}

\section{Inhibition of the PI3K pathway}

To confirm that the PI3K pathway positively regulates MTF-1 in response to metal ions, a first series of transient transfections were performed in 2 different cell lines, the immortalized human embryonic kidney HEK293 and the HCC HepG2 cells, treated, or not, with Torin 1, which inhibits both $\mathrm{MTOR}-\mathrm{C} 1$ and $\mathrm{MTOR}-\mathrm{C} 2$, or rapamycin, which specifically inhibits mTOR-C1. These 2 cell lines were selected to evaluate the action of the PI3K pathway on MTF-1 activity because it was inferred that the PI3K pathway is activated in HepG2 cells, thus repressing Mt gene expression compared with immortalized cells like HEK293 cells in which Mt genes are normally expressed and regulated. In addition, to ascertain that the results obtained with the (MREd) ${ }_{6}$-LUC reporter plasmid reflect the situation in the context of the native promoter, results obtained in cells transfected with the (MREd) ${ }_{6}$-LUC reporter plasmid and treated with Torin 1 were compared with those obtained in cells transfected with the reporter plasmids MT1-LUC and MT2A-LUC, containing 1843 bp of mouse Mt1 or 780 bp of human Mt2A gene 5' flanking sequences, respectively.

In HEK293 cells, the (MREd) ${ }_{6}$-LUC reporter plasmid was activated approximately 20 -fold in response to zinc induction (Fig. 1A). Treatment of cells with 100 and $250 \mathrm{nmol} / \mathrm{L}$ Torin 1 reduced (MREd) 6 -LUC zinc-induced expression by approximately $50 \%$ (Fig. 1A), thus confirming that the PI3K pathway positively regulates MTF-1. To determine whether the PI3K pathway regulates MTF-1 activity in the same manner both in the context of the artificial (MREd) ${ }_{6}$-LUC and native promoters, and both in HepG2 and HEK293 cells, similar transfections were performed with the MT1-LUC and the MT2A-LUC reporter plasmids in HepG2 cells. As shown in Fig. 1, the MT1-LUC plasmid was activated approximately 30 -fold by zinc (Fig. 1B), and the $h M T 2 A$ plasmid approximately 5-fold (Fig. 1C) in HepG2 cells. Notably, Torin 1 reduced MT1-LUC and MT2A-LUC zinc-induced expression by approximately $40 \%$ and $30 \%$, respectively (Figs. $1 \mathrm{~B}$ and $1 \mathrm{C}$ ), thus showing that the inhibitory effect of Torin 1 on MTF-1 activation is reproduced in the context of native promoter, and this inhibition is observed in both HepG2 cells and immortalized HEK293 cells. Thus, the PI3K pathway activates MTF-1 regardless of whether MTF-1 binding sites 
Fig. 2. Effect of rapamycin (A) and PTEN siRNAs (B) on (MREd) ${ }_{6}$-LUC expression. (A) HEK293 cells transfected by the PEI method with the reporter plasmids were serum-starved and preincubated for 30 min with the vehicle alone (0) or with $100 \mathrm{nmol} / \mathrm{L}$ of rapamycin, as indicated, and then treated or not with $100 \mu \mathrm{mol} / \mathrm{L} \mathrm{ZnCl}_{2}$ for $16 \mathrm{~h}$. Cell extracts were prepared, and measurement of LUC activity was performed as indicated in Fig. 1. (B) HEK293 cells transfected by the calcium phosphate method with a mixture of (MREd) 6 -LUC and pTK-rLUC as internal standard together with $250 \mathrm{ng}$ of negative control (Ctrl) or PTEN siRNAs were serum-starved and then treated, or not, with $100 \mu \mathrm{mol}^{\prime} \mathrm{L} \mathrm{ZnCl}$ for $16 \mathrm{~h}$. Cell extracts were prepared, and measurement of LUC activity was performed with a dual LUC kit. Results are expressed as percentage firefly LUC (fLUC) activity relative to the level directed by the Renilla LUC (rLUC) construct. The data represent the mean \pm S.D. of 3 independent experiments performed in triplicate. Significant differences between the control and treated samples are based on the one-way ANOVA followed by a Bonferroni post-hoc test $\left({ }^{* *}, p \leq 0.01\right.$;**, $\left.p \leq 0.001 ;{ }^{* * *}, p<0.0001\right)$.

A

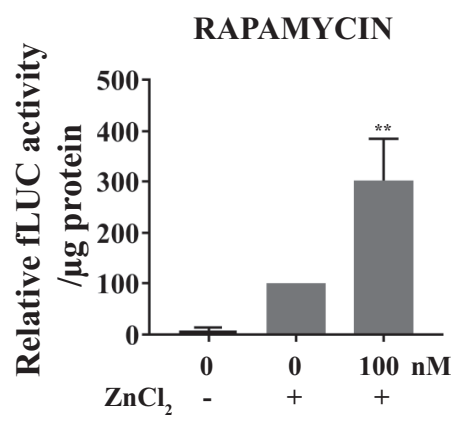

are in their natural context or organized in tandem in an artificial promoter.

In a second series of experiments, we used the mTOR-C1 inhibitor rapamycin. To note, activated mTOR-C1 inhibits PI3K-Akt signaling by blocking mTOR-C2 activity or other upstream molecules (Hsu et al. 2011; Liu et al. 2013). Therefore, inhibition of mTOR-C1 should upregulate MTF-1 if the PI3K pathway positively regulates MTF-1. Indeed, while the (MREd) ${ }_{6}$-LUC reporter plasmid was activated approximately 12 -fold in response to zinc induction (Fig. 2A), it was induced more than 35-fold in cells treated with rapamycin, thus indicating that the PI3K pathway positively regulates MTF-1.

Finally, we used siRNAs to downregulate PTEN, a phosphatase that antagonizes the PI3K signaling pathway. As for the inhibition of mTOR-C1, siRNAs directed towards PTEN should upregulate MTF-1 if the PI3K pathway positively controls MTF-1. As expected, zinc-induced (MREd) ${ }_{6}$-LUC activity was stimulated 40 -fold in response to zinc induction in cells treated with the PTEN siRNAs compared with 30-fold in cells treated with control siRNAs (Fig. 2B). PTEN siRNAs also increased basal (MREd) ${ }_{6}$-LUC expression almost 2-fold compared with the control siRNAs.

To ensure that the protein kinase inhibitors were effective in inhibiting the corresponding kinases, Western blot analyses were performed with extracts prepared from HEK293 cells treated with Torin 1, rapamycin, and the PTEN siRNAs. At the concentration of inhibitors used, the mTOR-C1 and mTOR-C2 complexes were efficiently inhibited, as measured by the levels of Phospho S6 (Ser240/ 244) and Akt phosphorylated on Thr308 and Ser473 (Figs. 3A and 3B). Similarly, although to a lesser extent, the PTEN levels were also reduced (Fig. 3C). However, the levels of pAkt (Thr308) and pAkt (Ser473) do not change significantly in cells treated with rapamycin (see Discussion).

\section{Inhibition of GSK-3}

Interestingly, Datta et al. (2007) also showed that inhibition of GSK-3 with LiCl inhibits Mt expression in HepG3 cells. They suggested that the interaction of $\mathrm{C} / \mathrm{EBP} \alpha$ with MTF-1, required for the activation of $M t$ gene expression, is induced by the phosphorylation of C/EBP $\alpha$ by GSK-3. Thus, the inhibition of GSK-3 by $\mathrm{LiCl}$ or by the activation of PI3K-Akt should abolish this interaction and abrogate $M t$ gene expression. In addition, we showed that treatment of mouse L cells with the PKC inhibitors Ro-31-8220 or
B

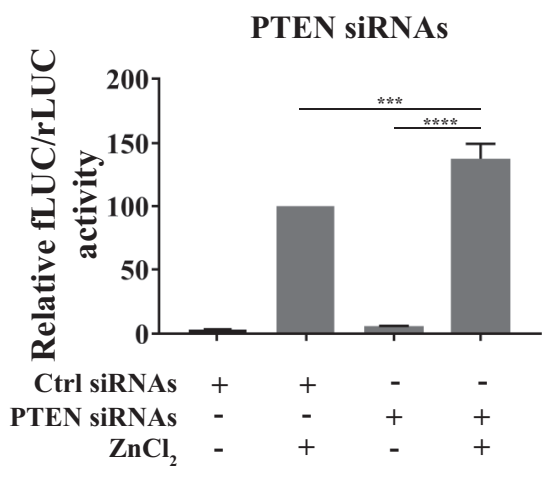

GF109203X completely abrogated metal induction of Mt mRNA, and zinc- and cadmium-stimulated expression of both MT1-LUC and (MREd) ${ }_{6}$-LUC in HepG2 cells (LaRochelle et al. 2001). However, these 2 agents are potent inhibitors of GSK-3 activity (Hers et al. 1999). This suggests that GSK-3 could positively regulate MTF-1 activity. To test this hypothesis, HEK293 cells were transfected with the (MREd) ${ }_{6}$-LUC reporter plasmid and treated, or not, with CHIR99021 (Ring et al. 2003) or LY2090314 (Zamek-Gliszczynski et al. 2013), 2 potent and specific GSK-3 inhibitors. The TOP-Flash plasmid (van de Wetering et al. 1997) was used as a positive control. This luciferase reporter construct contains a concatemer of the TCF/LEF binding site. Inhibition of GSK-3 leads to the stabilization of $\beta$-catenin, which then can bind the TCF site and activate LUC expression. Exposure of HEK293 cells to CHIR99021 or LY2090314 induced TOP-Flash luciferase activity (data not shown), thus confirming the inhibition of GSK-3. In addition, while the (MREd) ${ }_{6}^{-}$ LUC reporter plasmid was activated in control cells 50- (Fig. 4A) and 12-fold (Fig. 4B) in response to zinc induction, both GSK-3 inhibitors reduced zinc-induced (MREd) 6 -LUC expression by $60 \%$ (CHIR99021) and 40\% (LY2090314) (Fig. 4). This shows that GSK-3 positively regulates MTF-1 activity.

\section{Discussion}

Role of the PI3K pathway in regulation of MTF-1 activity

MTF-1 is reversibly activated to bind to DNA and to enhance Mt gene transcription in response to increased free zinc levels. Zinc is believed to lead to an allosteric change in MTF-1, causing exposure of zinc-fingers involved in DNA binding (Giedroc et al. 2001). In addition, phosphorylation is involved in the complete activation of MTF-1 in response to metals. Our previous study demonstrated that the PI3K pathway is essential for MTF-1 transactivation function (LaRochelle et al. 2001). In this study, we further investigated the effect of the PI3K pathway on the activity of MTF-1 in response to zinc ions. We performed transfection experiments in HEK293 and HepG 2 cells treated, or not, with Torin 1 and rapamycin, to inhibit protein kinases in the PI3K pathway. In addition, we also used specific siRNAs against PTEN. We compared the results obtained with the artificial (MREd) 6 -LUC reporter plasmid in cells treated with Torin 1 with those obtained with reporter plasmids containing 1843 and $877 \mathrm{bp}$ of the native mouse Mt1 and human Mt2A promoter DNA sequences, respectively. 
Fig. 3. Immunoblotting analyses. S6 (Ser240/244) and Akt (Thr308 and Ser473) phosphorylation were measured in HEK293 cells serum-starved and treated or not with either the vehicle alone (DMSO), 50 or $100 \mathrm{nmol} / \mathrm{L}$ of rapamycin (A), $100 \mathrm{or} 250 \mathrm{nmol} / \mathrm{L}$ of Torin 1 (B), and 250 ng of negative control (Ctrl) or PTEN siRNAs $(\mathrm{C})$, and $100 \mu \mathrm{mol} / \mathrm{L} \mathrm{ZnCl}_{2}$ for $16 \mathrm{~h}$. Cell extracts were prepared, and immunoblotting was performed as described in the section on Materials and methods. GAPDH was used as a loading control.



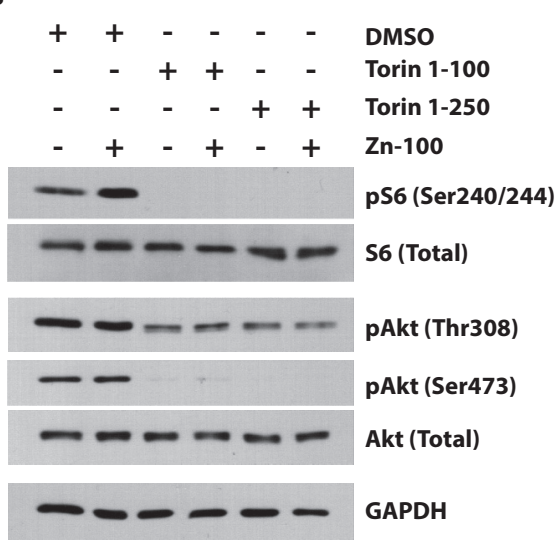

C

\begin{tabular}{|c|c|c|c|c|c|c|}
\hline+ & + & - & - & - & - & DMSO \\
\hline - & - & + & + & - & - & Ctrl siRNAs \\
\hline - & - & - & - & + & + & PTEN siRNAs \\
\hline - & + & - & + & - & + & $Z n-100$ \\
\hline- & 一 & - & 一 & - & - & pS6 (Ser240/244) \\
\hline- & & $\longrightarrow$ & - & - & - & S6 (Total) \\
\hline- & - & - & - & - & - & pAkt (Thr308) \\
\hline- & - & - & - & - & - & pAkt (Ser473) \\
\hline- & $\rightarrow$ & - & - & - & - & Akt (Total) \\
\hline$\rightarrow$ & - & 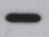 & $\longrightarrow$ & - & - & GAPDH \\
\hline- & - & - & + & 2 & $x^{2}$ & Low expo \\
\hline- & - & 一 & - & 一 & - & High expo \\
\hline
\end{tabular}

Fig. 4. Effect of CHIR99021 (A) and LY2090314 (B) on (MREd) $)_{6}$-LUC expression. HEK293 cells transfected with the reporter plasmid were serum-starved and pre-incubated for 30 min with the vehicle alone (0) or with $10 \mu \mathrm{mol} / \mathrm{L}$ of CHIR99021, or 10 or $20 \mathrm{nmol} / \mathrm{L}$ of LY2090314, as indicated, and then treated or not with $100 \mu \mathrm{mol} / \mathrm{L} \mathrm{ZnCl}_{2}$ for $16 \mathrm{~h}$. Cell extracts were prepared, and measurement of LUC activity was performed as indicated in Fig. 1. Results are expressed as relative firefly LUC (fLUC) activity per microgram $(\mu \mathrm{g})$ of total protein, and as a percentage relative to that of the control induced by zinc, which is taken as $100 \%$. The data represent the mean \pm S.D. of 3 independent experiments performed in triplicate. Significant differences between the control and treated samples are based on the one-way ANOVA followed by a Bonferroni post-hoc test $\left({ }^{*}, p \leq 0.05 ; * * * *, p<0.0001\right)$.
A

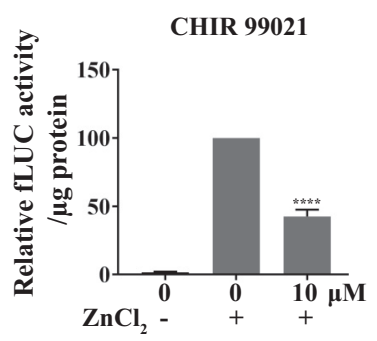

B

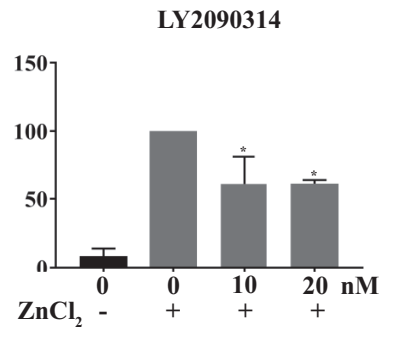

First, we showed that Torin 1, a mTOR-C1 and mTOR-C2 inhibitor, diminished the expression of the (MREd) ${ }_{6}$-LUC reporter, thus confirming that the PI3K pathway positively controls MTF-1 activity. Indeed, mTOR-C2 is required for the activation of Akt and, as expected, its inhibition downregulated Akt (Fig. 3B) and logically its downstream effectors, including MTF-1. Second, we obtained similar results with all 3 reporter plasmids. This shows that the (MREd) ${ }_{6}$-LUC reporter does not behave differently from the endogenous promoter with respect to PI3K signaling, as inferred by Datta et al. (2007), thus validating and confirming our previous results obtained with a (MREd) ${ }_{6}$-LUC reporter (LaRochelle et al. 2001). Third, inhibition of the PI3K pathway diminished MTF-1 activity in response to zinc in both immortalized kidney HEK293 and HCC HepG2 cells. This result does not support the contention that the PI3K pathway is activated in HepG2 cells in which it abrogates $M t$ gene expression by inhibiting GSK-3 (Datta et al. 2007). Fourth, to further confirm that the PI3K pathway positively regulates MTF-1, HEK293 cells were treated with rapamycin, which specifically inhibits mTOR-C1. Interestingly, it has been reported that activated mTOR-C1 downregulates the PI3K-mTOR-C2 axis through negative feedback loops (Hsu et al. 2011; Liu et al. 2013). Thus, if the PI3K pathway activates MTF-1 in response to zinc ions, (MREd) ${ }_{6}$-LUC should be stimulated by rapamycin, because inhibition of mTOR-C1 would upregulate the PI3K-mTOR-C2 axis. Notably, the activity of the (MREd) ${ }_{6}$-LUC reporter is increased in cells treated with rapamycin and zinc, compared with control cells treated with zinc only (Fig. 2A). This result supports the conclusion that the PI3K pathway positively regulates MTF-1 activity. The inhibition of mTOR-C1 should inhibit the activity of S6 kinase, an immediate downstream target of mTOR-C1, and enhance that of Akt. However, Fig. 3A shows that while rapamycin strongly inhibits phosphorylation of S6 kinase, thus confirming that mTOR-C1 was efficiently inhibited, contrary to what was expected, the phosphorylation status of Akt remains unchanged, which indicates that Akt was not activated. Thus, the activation of MTF-1 in response to rapamycin does not appear to result from the activation of Akt and of the PI3K pathway. However, the absence of a detectable Akt activation in rapamycin-treated cells could be the result of a feedback loop that negatively regulates Akt activity under prolonged activating conditions to avoid an hyperstimulation of the pathway, as reported by Manning and Toker (2017). If this is the case, then the activation of MTF- 1 in rapamycin-treated cells is the result of the activation of Akt, and confirms that the PI3K pathway activates MTF-1. Alternatively, the absence of Akt activation in rapamycin-treated cells would rather suggest the existence of mTOR-C1 downstream factors negatively regulating MTF-1 activity (Fig. 5). In support of this hypothesis, mTOR-C1 has been identified as a key negative regulator of bHLH leucine zipper transcription factor EB (TFEB) function (reviewed in Laplante and Sabatini 2013). Further experiments will be required to resolve this question. Fifth, siRNAs were used to perturb the PI3K pathway. We utilized siRNAs to inhibit PTEN, the negative regulator of the PI3K pathway. As for rapamycin, if the PI3K pathway activates MTF-1, inhibition of PTEN should stimulate (MREd) ${ }_{6}$-LUC activity. Indeed, as shown in Fig. 2B, PTEN siRNAs stimulated the (MREd) ${ }_{6}^{-}$ LUC reporter in response to zinc compared with control cells treated with non-specific siRNAs. However, in contradiction with these results, it has been reported that depletion of PTEN using siRNAs reduced $M t$ gene expression (Lin et al. 2012). The activation of MTF-1 in response to the activation of the PI3K pathway by the 
Fig. 5. Putative model of the signaling pathways involved in the activation of MTF-1. Zinc ions activate a receptor tyrosine kinase (RTK), which recruits and activates PI3K. PI3K then produces $\mathrm{PI}(3,4,5) \mathrm{P}_{3}$, which serves as a docking site for Akt and PDK1. Akt is phosphorylated by mTOR in complex 2 and PDK1. The activated Akt (Akt**) dissociates from the membrane and phosphorylates various target proteins including GSK-3 and TSC2, a negative regulator of Rheb, a RAS-related GTPase. Active Rheb helps activate mTOR in complex 1, thereby promoting protein synthesis by phosphorylating p70S6 kinase (S6K). Full activation of MTF-1 in response to zinc ions also requires the action of the JNK, CK2, and PKC signaling transduction pathways (LaRochelle et al. 2001; Saydam et al. 2002). Activation of MTF-1 by the PI3K pathway may involve an Akt signal transduction pathway targeting MTF-1 (broken arrows), or the inhibition by mTOR-C1 of a putative inhibitory protein (broken lines, downstream of $\mathrm{mTOR}-\mathrm{C} 1$ ). We show here that GSK-3 is involved in the activation of MTF-1 through an Aktindependent positive regulatory pathway (AIP). Activated GSK-3 could directly phosphorylate and activate MTF-1, or could affect MTF-1 through a signaling pathway converging on MTF-1, Alternatively, GSK-3 could affect MTF-1 by its inhibitory action on PTEN which antagonizes the PI3K signaling pathway. In addition, PTEN (Lin et al. 2012) and PP2A (Chen et al. 2014) (not illustrated) have been shown to interact with MTF-1 and regulate its activity. The kinases targeted by CHIR99021 (CHIR), LY2090314, Torin 1 and rapamycin are indicated. The question marks indicate putative pathways.

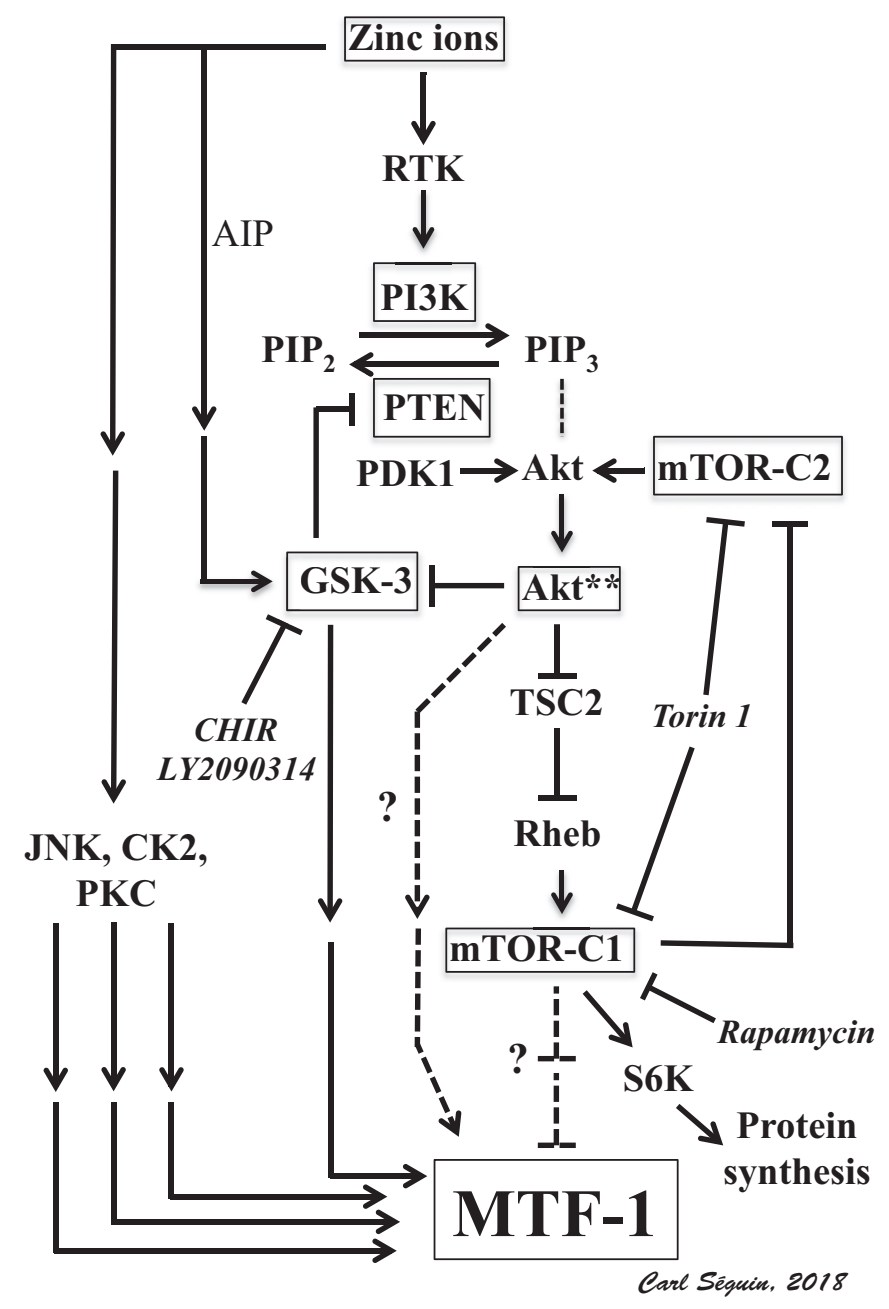

inhibition of mTOR-C1 and PTEN is in accordance with the downregulation of MTF-1 activity following the inhibition of the PI3K pathway with Torin 1 . Overall, the data presented here clearly show that the PI3K pathway positively regulates MTF-1 transcrip- tional activity both in the context of the native promoter and of an artificial promoter like (MREd) ${ }_{6}$-LUC, in immortalized HEK293 cells and in the HCC HepG2 cells. The reason for the apparent discrepancies between our original results (LaRochelle et al. 2001) as well as those presented here, and those of Datta et al. (2007) are not clear, but one possible explanation is a drift of cell lines in culture. Phenotypic drifts due to serial passages and transfers between laboratories are frequently encountered and may influence the outcome of the results (Geraghty et al. 2014).

The activity of MTF- 1 is controlled by multiple signal transduction kinase pathways, including JNK, PKC, CK2, a protein tyrosine kinase, as well as PTEN and PP2A (see the Introduction for references), which together contribute to the maximal activation of MTF-1. These kinases function in complex pathways ending with one or several endpoint kinases that phosphorylates and activates MTF-1. Full activation of MTF-1 in the presence of zinc ions requires the simultaneous activation of these multiples pathways. Inhibition of one of these pathways leaves largely unaffected the other pathways controlling MTF-1 activity. Thus, the residual activity of MTF-1 observed in the presence of Torin 1, CHIR99021, and LY2090314 likely represents the activity of MTF-1 that is under the control of the other kinase signalling pathways involved in the regulation of its transcriptional activity.

Analysing the role of the PI3K pathway in the regulation of MTF-1 activity is central to understanding the signal transduction mechanisms controlling intracellular zinc levels. Zinc is an essential transition metal in humans (Beyersmann and Haase 2001; Fukada et al. 2011) through its binding to thousands of proteins (Passerini et al. 2007). Zinc also functions as a signaling molecule at the cellular level, and thus steady-state concentrations of free intracellular zinc ions are maintained within narrow limits by zinc homeostatic molecules including cytosolic zinc-binding proteins, such as MTs, two families of transport proteins, the ZIP channels, which increase cytosolic zinc, and the ZnT transporters, which remove zinc from the cytosol, and sensors of cytoplasmic free zinc ions like MTF-1 (Colvin et al. 2010; Kambe 2011). If free zinc concentrations increase, zinc ions will bind to MTF-1 and effect changes in the expression of genes encoding zinc homeostatic proteins. Notably, MTF-1 is the only zinc sensor protein that has been characterized in multicellular organisms (Colvin et al. 2010; Choi and Bird 2014; Hardyman et al. 2016). Interestingly, Taylor et al. (2012) have shown that extracellular zinc results in ZIP7-dependent release of zinc from the endoplasmic reticulum, resulting in activation of multiple downstream pathways including tyrosine kinases, MAP kinases, mTOR, GSK-3, and PI3K-Akt (Nimmanon et al. 2017). In this context, it is not surprising that the activated PI3K pathway converging on MTF-1 activates MTF-1, thus inducing $M t$ genes and other zinc homeostatic protein coding genes.

\section{GSK-3 is required for the activation of MTF-1}

It has been proposed that GSK-3 is essential for Mt gene expression in HepG2 cells because phosphorylation of C/EBP $\alpha$ by GSK-3 is required for the interaction of C/EBP $\alpha$ with MTF- 1 and the induction of Mt expression (Datta et al. 2007). According to this model, activation of PI3K, which results in the activation of Akt and the inhibition of GSK-3, explains the upregulation of Mt expression in response to the inhibition of PI3K.

In this study, we wished instead to determine whether GSK-3 is required for the activation of MTF-1. Using 2 different GSK-3 specific inhibitors (CHIR99021 and LY2090314), we showed that, while inhibition of GSK-3 had little if any effect on constitutive MTF-1 activity, it strongly inhibited its activation in response to zinc ions (Fig. 4), thus clearly showing that GSK-3 is essential for the activation of MTF-1 in response to zinc. Thus, these results do not support the contention that activation of the PI3K pathway abrogates Mt expression by inhibiting GSK-3 but, more importantly, they reveal the existence of an MTF-1 Akt-independent GSK-3 activation 
pathway (Fig. 5, AIP). Our results also exclude the possibility that in non-induced cells, active GSK-3 negatively regulates MTF-1 and, upon zinc activation of the PI3K pathway, GSK-3 being phosphorylated and inactivated by Akt, MTF- 1 is no longer inhibited by GSK-3, thus allowing a direct activation of MTF-1 through one of the kinases in the PI3K pathway. In such a situation, inhibition of GSK-3 should increase MTF-1 activity in the non-induced state and possibly potentiate its activation in response to zinc, which is not the case. Still, the activation of the PI3K pathway is required for MTF-1 activation, and thus is logically involved the activation of Akt and the phosphorylation-inhibition of GSK-3 on Ser-9 and Ser-21 by Akt (Hermida et al. 2017). Consequently, there must be one or more other zinc-induced signaling events activating GSK-3, which are required for full activation of MTF-1. Notably, zinc treatments have been shown to activate GSK-3 (An et al. 2005; McClung et al. 2007; Min et al. 2007). Thus, we hypothesize the existence of a zinc-activated PI3K-Akt independent pathway activating GSK-3 (Fig. 5, AIP). This signaling pathway would create a GSK-3-activated conformation capable of directly or indirectly phosphorylating and enhancing MTF-1 activity. Alternatively, zinc-activated GSK-3 could phosphorylate and inactivate PTEN, which would enhance zincinduced MTF-1 activation by the PI3K pathway. In fact, it has been shown that zinc treatment results in a reduction of the PTEN protein level in neural and airway epithelial cells (Wu et al. 2003; Kwak et al. 2010). In addition, PTEN can be phosphorylated by GSK-3 (Al-Khouri et al. 2005; Min et al. 2007; Jang et al. 2013), and the phosphorylation of Thr-366 in PTEN by GSK-3 plays a role in destabilizing the PTEN protein (Maccario et al. 2007; Hermida et al. 2017). Moreover, inhibition of GSK-3 suppressed PTEN phosphorylation levels and enhanced Akt phosphorylation in bone-marrow macrophages (Jang et al. 2013). Further experiments will be required to understand the mechanisms by which GSK-3 and PTEN control MTF-1 activity and Mt expression.

In conclusion, taken together, these results show that the PI3K pathway and GSK-3 positively regulate MTF-1 transactivation in response to zinc ions.

\section{Acknowledgements}

C.S. is grateful to Alan Anderson and Mathieu Laplante for critical reading of the manuscript, and to Mathieu Laplante for helpful discussions on the PI3K pathway.

\section{References}

Al-Khouri, A.M., Ma, Y., Togo, S.H., Williams, S., and Mustelin, T. 2005. Cooperative phosphorylation of the tumor suppressor phosphatase and tensin homologue (PTEN) by casein kinases and glycogen synthase kinase $3 \beta$. J. Biol. Chem. 280(42): 35195-35202. doi:10.1074/jbc.M503045200. PMID:16107342.

An, W.L., Bjorkdahl, C., Liu, R., Cowburn, R.F., Winblad, B., and Pei, J.J. 2005. Mechanism of zinc-induced phosphorylation of p70 S6 kinase and glycogen synthase kinase $3 \beta$ in SH-SY5Y neuroblastoma cells. J. Neurochem. 92(5): 1104-1115. doi:10.1111/j.1471-4159.2004.02948.x. PMID:15715661.

Babula, P., Masarik, M., Adam, V., Eckschlager, T., Stiborova, M., Trnkova, L., et al. 2012. Mammalian metallothioneins: properties and functions. Metallomics, 4(8): 739-750. doi:10.1039/c2mt20081c. PMID:22791193.

Bahadorani, S., Mukai, S., Egli, D., and Hilliker, A.J. 2010. Overexpression of metal-responsive transcription factor (MTF-1) in Drosophila melanogaster ameliorates life-span reductions associated with oxidative stress and metal toxicity. Neurobiol. Aging, 31(7):1215-1226. doi:10.1016/j.neurobiolaging.2008. 08.001. PMID:18775584.

Bellingham, S.A., Coleman, L.A., Masters, C.L., Camakaris, J., and Hill, A.F. 2009. Regulation of prion gene expression by transcription factors SP1 and metal transcription factor-1. J. Biol. Chem. 284(2): 1291-1301. doi:10.1074/jbc.M804755200. PMID:18990686.

Beyersmann, D., and Haase, H. 2001. Functions of zinc in signaling, proliferation and differentiation of mammalian cells. Biometals, 14(3-4): 331-341. doi:10. 1023/A:1012905406548. PMID:11831463.

Bittel, D.C., Smirnova, I.V., and Andrews, G.K. 2000. Functional heterogeneity in the zinc fingers of metalloregulatory protein metal response elementbinding transcription factor-1. J. Biol. Chem. 275(47): 37194-37201. doi:10.1074/ jbc.M003863200. PMID:10958790.

Brown, E.J., Albers, M.W., Shin, T.B., Ichikawa, K., Keith, C.T., Lane, W.S., and Schreiber, S.L. 1994. A mammalian protein targeted by G1-arresting rapamycinreceptor complex. Nature, 369(6483): 756-758. doi:10.1038/369756a0. PMID: 8008069.

Chen, L., Ma, L., Bai, Q., Zhu, X., Zhang, J., Wei, Q., et al. 2014. Heavy metal- induced metallothionein expression is regulated by specific protein phosphatase 2A complexes. J. Biol. Chem. 289(32): 22413-22426. doi:10.1074/jbc. M114.548677. PMID:24962574.

Choi, S., and Bird, A.J. 2014. Zinc'ing sensibly: controlling zinc homeostasis at the transcriptional level. Metallomics, 6(7): 1198-1215. doi:10.1039/C4MT00064A. PMID:24722954.

Colvin, R.A., Holmes, W.R., Fontaine, C.P., and Maret, W. 2010. Cytosolic zinc buffering and muffling: their role in intracellular zinc homeostasis. Metallomics, 2(5): 306-317. doi:10.1039/b926662c. PMID:21069178.

Coyle, P., Philcox, J.C., Carey, L.C., and Rofe, A.M. 2002. Metallothionein: the multipurpose protein. Cell. Mol. Life Sci. 59(4): 627-647. doi:10.1007/s00018002-8454-2. PMID:12022471.

Datta, J., Majumder, S., Kutay, H., Motiwala, T., Frankel, W., Costa, R., et al. 2007. Metallothionein expression is suppressed in primary human hepatocellular carcinomas and is mediated through inactivation of CCAAT/Enhancer Binding Protein $\alpha$ by phosphatidylinositol 3-kinase signaling cascade. Cancer Res. 67(6): 2736-2746. doi:10.1158/0008-5472.CAN-06-4433. PMID:17363595.

Dibble, C.C., and Cantley, L.C. 2015. Regulation of mTORC1 by PI3K signaling. Trends Cell Biol. 25(9): 545-555. doi:10.1016/j.tcb.2015.06.002. PMID:26159692.

Ding, H., Wu, B., Wang, H., Lu, Z., Yan, J., Wang, X., et al. 2010. A novel loss-offunction DDAH1 promoter polymorphism is associated with increased susceptibility to thrombosis stroke and coronary heart disease. Circ. Res. 106(6): 1145-1152. doi:10.1161/CIRCRESAHA.109.215616. PMID:20167924.

Dubé, A., Harrisson, J.F., Saint-Gelais, G., and Séguin, C. 2011. Hypoxia acts through multiple signaling pathways to induce metallothionein transactivation by the metal-responsive transcription factor-1 (MTF-1). Biochem. Cell Biol. 89(6): 562-577. doi:10.1139/o11-063. PMID:22087877.

Faraonio, R., Moffatt, P., LaRochelle, O., St-Arnaud, R., Schipper, H.M., and Séguin, C. 2000. Characterization of cis-acting elements in the promoter of the mouse metallothionein-3 gene. Activation of gene expression during neuronal differentiation of P19 embryonal carcinoma cells. Eur. J. Biochem. 267(6): 1743-1753. PMID:10712606

Fukada, T., Yamasaki, S., Nishida, K., Murakami, M., and Hirano, T. 2011. Zinc homeostasis and signaling in health and diseases. J. Biol. Inorg. Chem. 16(7): 1123-1134. doi:10.1007/s00775-011-0797-4. PMID:21660546.

Geraghty, R.J., Capes-Davis, A., Davis, J.M., Downward, J., Freshney, R.I., Knezevic, I., et al. 2014. Guidelines for the use of cell lines in biomedical research. Br. J. Cancer, 111(6): 1021-1046. doi:10.1038/bjc.2014.166. PMID:25117809.

Gharbi, S.I., Zvelebil, M.J., Shuttleworth, S.J., Hancox, T., Saghir, N., Timms, J.F., and Waterfield, M.D. 2007. Exploring the specificity of the PI3K family inhibitor LY294002. Biochem. J. 404: 15-21. doi:10.1042/BJ20061489. PMID:17302559.

Giedroc, D.P., Chen, X., and Apuy, J.L. 2001. Metal response element (MRE)binding transcription factor-1 (MTF-1): structure, function, and regulation. Antioxid. Redox Signaling, 3(4): 577-596. doi:10.1089/15230860152542943.

Green, C.J., Lichtlen, P., Huynh, N.T., Yanovsky, M., Laderoute, K.R., Schaffner, W., and Murphy, B.J. 2001. Placenta growth factor gene expression is induced by hypoxia in fibroblasts: a central role for metal transcription factor-1. Cancer Res. 61(6): 2696-2703. PMID:11289150.

Grzywacz, A., Gdula-Argasińska, J., Muszyńska, B., Tyszka-Czochara, M., Librowski, T., and Opoka, W. 2015. Metal responsive transcription factor 1 (MTF-1) regulates zinc dependent cellular processes at the molecular level. Acta Biochim. Pol. 62(3): 491-498. doi:10.18388/abp.2015_1038. PMID: 26336656.

Gulhati, P., Cai, Q., Li, J., Liu, J., Rychahou, P.G., Qiu, S., et al. 2009. Targeted inhibition of mammalian target of rapamycin signaling inhibits tumorigenesis of colorectal cancer. Clin. Cancer Res. 15(23): 7207-7216. doi:10.1158/10780432.CCR-09-1249. PMID:19934294.

Günes, C., Heuchel, R., Georgiev, O., Müller, K.H., Lichtlen, P., Blüthmann, H., et al. 1998. Embryonic lethality and liver degeneration in mice lacking the metal-responsive transcriptional activator MTF-1. EMBO J. 17(10): 2846-2854. doi:10.1093/emboj/17.10.2846. PMID:9582278.

Günther, V., Lindert, U., and Schaffner, W. 2012. The taste of heavy metals: gene regulation by MTF-1. Biochim. Biophys. Acta, Mol. Cell Res. 1823(9): 14161425. doi:10.1016/j.bbamcr.2012.01.005

Hardyman, J.E.J., Tyson, J., Jackson, K.A., Aldridge, C., Cockell, S.J., Wakeling, L.A., et al. 2016. Zinc sensing by metal-responsive transcription factor 1 (MTF1) controls metallothionein and ZnT1 expression to buffer the sensitivity of the transcriptome response to zinc. Metallomics, 8(3): 337-343. doi:10.1039/C5MT00305A. PMID:26824222.

Haroon, Z.A., Amin, K., Lichtlen, P., Sato, B., Huynh, N.T., Wang, Z., et al. 2004. Loss of metal transcription factor-1 suppresses tumor growth through enhanced matrix deposition. FASEB J. 18(11): 1176-1184. doi:10.1096/fj.03-1205com. PMID: 15284217.

Hermida, M.A., Dinesh Kumar, J., and Leslie, N.R. 2017. GSK3 and its interactions with the PI3K/AKT/mTOR signalling network. Adv. Biol. Regul. 65: 5-15. doi: 10.1016/j.jbior.2017.06.003. PMID:28712664.

Hers, I., Tavaré, J.M., and Denton, R.M. 1999. The protein kinase C inhibitors bisindolylmaleimide I (GF 109203x) and IX (Ro 31-8220) are potent inhibitors of glycogen synthase kinase-3 activity. FEBS Lett. 460(3): 433-436. doi:10.1016/ S0014-5793(99)01389-7. PMID:10556511.

Heuchel, R., Radtke, F., Georgiev, O., Stark, G., Aguet, M., and Schaffner, W. 1994. 
The transcription factor MTF-1 is essential for basal and heavy metal-induced metallothionein gene expression. EMBO J. 13(12): 2870-2875. PMID:8026472.

Hoang, B., Frost, P., Shi, Y., Belanger, E., Benavides, A., Pezeshkpour, G., et al. 2010. Targeting TORC2 in multiple myeloma with a new mTOR kinase inhibitor. Blood, 116(22): 4560-4568. doi:10.1182/blood-2010-05-285726. PMID:20686120.

Hogstrand, C., Zheng, D., Feeney, G., Cunningham, P., and Kille, P. 2008. Zinccontrolled gene expression by metal-regulatory transcription factor 1 (MTF1) in a model vertebrate, the zebrafish. Biochem. Soc. Trans. 36(6): 1252-1257. doi:10.1042/BST0361252.

Hsu, P.P., Kang, S.A., Rameseder, J., Zhang, Y., Ottina, K.A., Lim, D., et al. 2011. The mTOR-regulated phosphoproteome reveals a mechanism of mTORC1mediated inhibition of growth factor signaling. Science, 332(6035): 13171322. doi:10.1126/science.1199498. PMID:21659604

Janes, M.R., Limon, J.J., So, L., Chen, J., Lim, R.J., Chavez, M.A., et al. 2010. Effective and selective targeting of leukemia cells using a TORC1/2 kinase inhibitor. Nat. Med. 16(2): 205-213. doi:10.1038/nm.2091. PMID:20072130.

Jang, H.D., Noh, J.Y., Shin, J.H., Lin, J.J., and Lee, S.Y. 2013. PTEN regulation by the Akt/GSK-3 $\beta$ axis during RANKL signaling. Bone, 55(1): 126-131. doi:10.1016/j. bone.2013.02.005. PMID:23419777.

Kambe, T. 2011. An overview of a wide range of functions of ZnT and Zip zinc transporters in the secretory pathway. Biosci., Biotechnol., Biochem. 75(6): 1036-1043. doi:10.1271/bbb.110056. PMID:21670538.

Kim, J.H., Jeon, J., Shin, M., Won, Y., Lee, M., Kwak, J.S., et al. 2014. Regulation of the catabolic cascade in osteoarthritis by the zinc-ZIP8-MTF1 axis. Cell, 156(4): 730-743. doi:10.1016/j.cell.2014.01.007. PMID:24529376.

Kwak, Y.D., Wang, B., Pan, W., Xu, H., Jiang, X., and Liao, F.F. 2010. Functional interaction of phosphatase and tensin homologue (PTEN) with the E3 ligase NEDD4-1 during neuronal response to zinc. J. Biol. Chem. 285(13): 9847-9857. doi:10.1074/jbc.M109.091637. PMID:20100827.

Labbé, S., Prévost, J., Remondelli, P., Leone, A., and Séguin, C. 1991. A nuclear factor binds to the metal regulatory elements of the mouse gene encoding metallothionein-I. Nucleic Acids Res. 19(15): 4225-4231. doi:10.1093/nar/19.15. 4225. PMID:1870976.

Laity, J.H., and Andrews, G.K. 2007. Understanding the mechanisms of zincsensing by metal-response element binding transcription factor-1 (MTF-1) Arch. Biochem. Biophys. 463(2): 201-210. doi:10.1016/j.abb.2007.03.019. PMID: 17462582

Laplante, M., and Sabatini, D.M. 2012. mTOR signaling in growth control and disease. Cell, 149(2): 274-293. doi:10.1016/j.cell.2012.03.017. PMID:22500797.

Laplante, M., and Sabatini, D.M. 2013. Regulation of mTORC1 and its impact on gene expression at a glance. J. Cell Sci. 126(8): 1713-1719. doi:10.1242/jcs. 125773. PMID:23641065.

LaRochelle, O., Gagné, V., Charron, J., Soh, J.W., and Séguin, C. 2001. Phosphorylation is involved in the activation of metal-regulatory transcription factor 1 in response to metal ions. J. Biol. Chem. 276(45): 41879-41888. doi:10.1074/jbc.M108313200. PMID:11551972.

Lee, J., Li, Z., Brower-Sinning, R., and John, B. 2007. Regulatory circuit of human microRNA biogenesis. PLoS Comput. Biol. 3(4): e67. doi:10.1371/journal.pcbi. 0030067. PMID:17447837.

Lichtlen, P., and Schaffner, W. 2001. Putting its fingers on stressful situations: the heavy metal-regulatory transcription factor MTF-1. Bioessays, 23(11): 1010-1017. doi:10.1002/bies.1146. PMID:11746217.

Lin, M.C., Liu, Y.C., Tam, M.F., Lu, Y.J., Hsieh, Y.T., and Lin, L.Y. 2012. PTEN interacts with metal-responsive transcription factor 1 and stimulates its transcriptional activity. Biochem. J. 441(1): 367-377. doi:10.1042/BJ20111257. PMID: 21883094

Liu, P., Gan, W., Inuzuka, H., Lazorchak, A.S., Gao, D., Arojo, O., et al. 2013. Sin1 phosphorylation impairs mTORC2 complex integrity and inhibits downstream Akt signalling to suppress tumorigenesis. Nat. Cell Biol. 15(11): 13401350. doi:10.1038/ncb2860. PMID:24161930.

Maccario, H., Perera, N.M., Davidson, L., Downes, C.P., and Leslie, N.R. 2007. PTEN is destabilized by phosphorylation on $\mathrm{Thr}^{366}$. Biochem. J. 405: 439-444. doi:10.1042/BJ20061837. PMID:17444818

Manning, B.D., and Toker, A. 2017. AKT/PKB signaling: navigating the network. Cell, 169(3): 381-405. doi:10.1016/j.cell.2017.04.001. PMID:28431241.

McClung, J.P., Tarr, T.N., Barnes, B.R., Scrimgeour, A.G., and Young, A.J. 2007. Effect of supplemental dietary zinc on the mammalian target of rapamycin (mTOR) signaling pathway in skeletal muscle and liver from post-absorptive mice. Biol. Trace Elem. Res. 118(1): 65-76. doi:10.1007/s12011-007-0018-8. PMID: 17848732 .
McHugh, P.C., Wright, J.A., and Brown, D.R. 2011. Transcriptional regulation of the beta-synuclein 5 '-promoter metal response element by metal transcription factor-1. PLoS One, 6(2): e17354. doi:10.1371/journal.pone.0017354. PMID: 21386983.

Min, Y.K., Lee, J.E., and Chung, K.C. 2007. Zinc induces cell death in immortalized embryonic hippocampal cells via activation of Akt-GSK-3 $\beta$ signaling. Exp. Cell Res. 313(2): 312-321. doi:10.1016/j.yexcr.2006.10.013. PMID:17098228.

Nimmanon, T., Ziliotto, S., Morris, S., Flanagan, L., and Taylor, K.M. 2017. Phosphorylation of zinc channel ZIP7 drives MAPK, PI3K and mTOR growth and proliferation signalling. Metallomics, 9(5): 471-481. doi:10.1039/C6MT00286B. PMID:28205653.

Okazaki, Y., Miura, N., Satoh, M., Imura, N., and Naganuma, A. 1998. Metallothioneinmediated resistance to multiple drugs can be induced by several anticancer drugs in mice. Biochem. Biophys. Res. Commun. 245(3): 815-818. doi:10.1006 bbrc.1998.8509. PMID:9588197.

Passerini, A., Andreini, C., Menchetti, S., Rosato, A., and Frasconi, P. 2007. Predicting zinc binding at the proteome level. BMC Bioinf. 8: 39. doi:10.1186/14712105-8-39.

Ring, D.B., Johnson, K.W., Henriksen, E.J., Nuss, J.M., Goff, D., Kinnick, T.R., et al. 2003. Selective glycogen synthase kinase 3 inhibitors potentiate insulin activation of glucose transport and utilization in vitro and in vivo. Diabetes, 52(3): 588-595. doi:10.2337/diabetes.52.3.588. PMID:12606497.

Roy, V., Ghani, K., and Caruso, M. 2010. A dominant-negative approach that prevents diphthamide formation confers resistance to pseudomonas exotoxin A and diphtheria toxin. PLoS One, 5(12): e15753. doi:10.1371/journal. pone.0015753. PMID:21203470.

Sambrook, J., Fritsch, E.F., and Maniatis, T. 1989. Molecular cloning: a laboratory manual. Cold Spring Harbor Laboratory Press, Cold Spring Harbor, N.Y

Satoh, M., Aoki, Y., and Tohyama, C. 1997. Protective role of metallothionein in renal toxicity of cisplatinum. Cancer Chemother. Pharmacol. 40(4): 358-362. doi:10.1007/s002800050670. PMID:9225956.

Saydam, N., Adams, T.K., Steiner, F., Schaffner, W., and Freedman, J.H. 2002. Regulation of metallothionein transcription by the metal-responsive transcription factor MTF-1: identification of signal transduction cascades that control metal-inducible transcription. J. Biol. Chem. 277(23): 20438-20445. doi:10.1074/jbc.M110631200. PMID:11923282.

Shi, Y., Amin, K., Sato, B.G., Samuelsson, S.J., Sambucetti, L., Haroon, Z.A., et al. 2010. The metal-responsive transcription factor-1 protein is elevated in human tumors. Cancer Biol. Ther. 9(6): 469-476. doi:10.4161/cbt.9.6.10979. PMID:20087061.

Smirnova, I.V., Bittel, D.C., Ravindra, R., Jiang, H., and Andrews, G.K. 2000. Zinc and cadmium can promote rapid nuclear translocation of metal response element-binding transcription factor-1. J. Biol. Chem. 275(13): 9377-9384. doi: 10.1074/jbc.275.13.9377. PMID:10734081.

Taylor, K.M., Hiscox, S., Nicholson, R.I., Hogstrand, C., and Kille, P. 2012. Protein kinase CK2 triggers cytosolic zinc signaling pathways by phosphorylation of zinc channel ZIP7. Sci. Signaling, 5(210): ra11. doi:10.1126/scisignal.2002585. PMID:22317921.

van de Wetering, M., Cavallo, R., Dooijes, D., van Beest, M., van Es, J., Loureiro, J., et al. 1997. Armadillo coactivates transcription driven by the product of the Drosophila segment polarity gene dTCF. Cell, 88(6): 789-799. doi:10.1016/S00928674(00)81925-X. PMID:9118222.

van Loo, K.M.J., Schaub, C., Pitsch, J., Kulbida, R., Opitz, T., Ekstein, D., et al. 2015. Zinc regulates a key transcriptional pathway for epileptogenesis via metal-regulatory transcription factor 1 . Nat. Commun. 6: 8688. doi:10.1038/ ncomms9688. PMID:26498180.

Wu, W., Wang, X., Zhang, W., Reed, W., Samet, J.M., Whang, Y.E., and Ghio, A.J. 2003. Zinc-induced PTEN protein degradation through the proteasome pathway in human airway epithelial cells. J. Biol. Chem. 278(30): 28258-28263. doi:10.1074/jbc.M303318200. PMID:12743124.

Zamek-Gliszczynski, M.J., Abraham, T.L., Alberts, J.J., Kulanthaivel, P., Jackson, K.A., Chow, K.H., et al. 2013. Pharmacokinetics, metabolism, and excretion of the glycogen synthase kinase-3 inhibitor LY2090314 in rats, dogs, and humans: a case study in rapid clearance by extensive metabolism with low circulating metabolite exposure. Drug Metab. Dispos. 41(4): 714726. doi:10.1124/dmd.112.048488. PMID:23305709.

Zhao, W.J., Song, Q., Wang, Y.H., Li, K.J., Mao, L., Hu, X., et al. 2014. Zn-responsive proteome profiling and time-dependent expression of proteins regulated by MTF-1 in A549 cells. PLoS One, 9(8): e105797. doi:10.1371/journal.pone. 0105797. PMID:25162517. 